\title{
Libertad y tradición: los Estudios Generales y el devenir histórico de la Universidad Santo Tomás ${ }^{1}$
}

Juan Sebastián Ballén Rodríguez*

\section{Introducción a la problemática}

En el presente capítulo proponemos analizar la idea de la formación integral y de la enseñanza de las humanidades en la Universidad Santo Tomás (Estudios Generales), en la perspectiva socio-histórica de las luchas jurídicas y académicas libradas al interior del tomismo

1 Este trabajo es fruto de las investigaciones adelantadas al interior del grupo Anagnostes. Apartes de este trabajo se encuentran en la línea de estudios sobre tomísticas y ciencia ilustrada en los siglos XVII y XVIII en el Virreinato de la Nueva Granada y que ha venido estudiando el investigador desde el año 2012 hasta la fecha. Este trabajo se presentó en un evento académico promovido por la Unidad de Humanidades de la Universidad Santo Tomás en la ciudad de Villavicencio, para el primer semestre del 2014.

* Licenciatura en Filosofía y Lengua Castellana, Universidad Santo Tomás, Bogotá; magíster en Filosofía, Universidad Javeriana, Bogotá. Ha participado en varias convocatorias Fodeín de la UsTA con el Grupo de investigación Anagnostes, del Departamento de Humanidades y Formación Integral. 
español y de su traslado a América. Este fenómeno se hace visible, sobre todo, en las dinámicas evangelizadoras y educativas agenciadas por el cristianismo colonial. En estas luchas se ponen en juego las nociones de libertad y tradición, categorías filosóficas y pedagógicas que, leídas a la luz de los procesos socio-históricos que subyacen a la aparición de las corporaciones universitarias en la colonia neogranadina, presentan implicaciones en la concepción de ciencias humanas, un proyecto educativo que se transparenta en el modelo pedagógico de la Universidad Santo Tomás. Como se verá al final del estudio, una de las preocupaciones latentes en el modelo pedagógico del ideario educativo dominicano propende por una formación humanista que promueva la relación dialógica entre la pregunta y la respuesta, la autonomía y la tradición, el encuentro gnoseológico entre el discípulo y el maestro.

Abordaremos nuestro planteamiento a partir de una lectura histórica al proceso de conformación de las primeras corporaciones universitarias en la América colonial. Luego mostraremos el influjo ejercido por el modelo universitario de Salamanca en la conformación de la Universidad Tomística de Santa Fe, y de allí centraremos nuestra atención en la noción de la libertad, que fue erigida en las perspectivas moral y jurídica por la segunda escolástica española y la cual tendrá relación con el fenómeno sociológico del cristianismo colonial. Finalmente, destacaremos el sentido pedagógico y filosófico de los conceptos de libertad y tradición en la perspectiva educativa que fomenta la orden dominicana, de cara al que hacer de las humanidades en la Universidad Santo Tomás.

\section{Las humanidades y la historia de las corporaciones universitarias en la Colonia}

La palabra universitas proviene del lenguaje jurídico y hace alusión al gremio de personas (studium generale) reunidas bajo una 
relación espontánea de maestros-discípulos, cuya preocupación fundamental buscaba esclarecer la verdad de la ciencia y las disciplinas. Para finales del siglo xv el lenguaje universitario equiparó las palabras universitas y studium para señalar los gremios o grupos dedicados a la ciencia. El studium se convirtió en el apelativo para señalar el ejercicio académico de la institución universitaria, particularmente con la facultad para la distribución de las artes, en donde se impartía teología, derecho y medicina.

La universidad es un lugar donde se promueve la universitas facultam (lugar en el que se representan todas las facultades del conocimiento). Sin embargo, ¿qué representa la unidad en la universidad?, ¿las ramas del saber o facultades? ¿ $\mathrm{O}$ la filosofía y el sentido común que orienta el norte de la institución educativa? Para san Isidoro de Sevilla, tratadista y pensador del modelo educativo medieval primitivo, solo la disciplina y el esfuerzo metodológico salvará a la universidad de lo azaroso o lo opinable: "Mientras que el arte es aquello que puede ser de otra forma, la disciplina versa sobre cosas que no pueden ser de otra manera. Pues cuando después de discutido, algo se pone claro, es 'disciplina'; cuando se trata de algo opinable y sólo verosímil, se llama 'arte"' (San Isidoro de Sevilla s. vii).

La lectio (lección o texto), la questio (pregunta o interrogante de orientación) y la disputatio (discusión debate) son pasos metodológicos concebidos al interior de los estudios conventuales, principalmente bajo su programa curricular o ratio studiorum (plan de estudios). La lección del maestro era el objeto de estudio y el lugar a partir del cual se referenciaba el conocimiento; la pregunta y la interrogación, se originaba a partir de la consistencia de los argumentos, las distintas opiniones tenidas por la tradición a favor o en contra de las premisas desarrollada por la propuesta argumentativa; finalmente la disputa, momento en donde los estudiantes junto al maestro indagaban y demarcaban los límites y las posibilidades que se generaban a partir de la lección impartida. 
Este ejercicio era realmente el método que hizo del proyecto educativo medieval un momento sólido y estelar en la historia de las ideas pedagógicos

En este orden de ideas la misión pedagógica y filosófica de la universidad no elude el compromiso de propender por un proyecto educativo que le apuesta a una teleología (teoría de los fines), fincada en la idea de que las potencias humanas son transformables y susceptibles de perfectibilidad.

Las capacidades reflexivas, emotivas, socio-comunicativas y lúdico-simbólicas hacen parte del proyecto de profesionalización de los individuos. Tal apuesta educativa requiere de las humanidades para la formación no solo de sujetos capaces en la solución de los problemas científico-técnicos que surgen en las dinámicas laborales y de investigación en un mundo globalizado, virtual y abierto, sino también diestros en la solución de los problemas que surgen alrededor de la ciudadanía y el derecho internacional, el multiculturalismo y la migración de las poblaciones, la responsabilidad de empresa y la conciencia ecológica, la relación entre el individuo y la alteridad, etc. (Nussbaum, 2010).

En otras palabras, el proyecto pedagógico que se trasparenta en la finalidad educativa de la USTA, a saber, la formación integral, tiene antecedentes históricos en el humanismo cristiano tomista de la escolástica que se cultivará tanto en el modelo conventual regentado por los de la Orden de Predicadores en el año de 1550 en el Convento del Rosario, como en la emulación de la institución Universitaria de la primera mitad del siglo XVII: nos referimos a la Universidad de Salamanca y que fue fundada en el siglo XIII por el rey Alfonso IX.

Tres centurias siguieron antes de que se formaran los primeros claustros universitarios en América. La Universidad Tomística de Santa Fe (hoy conocida como la Universidad Santo Tomás) tiene antecedentes en la institución universitaria española, particularmente en dos tipos de regímenes educativos: el modelo conventual 
y la Universidad de Salamanca. Tal y como lo ha expresado de manera erudita y detallada el padre José Abel Salazar en Los Estudios eclesiásticos superiores en el Nuevo Reino de Granada (1563-1810), se entiende que los estudios superiores fueron agenciados en Colombia por las órdenes religiosas. Este plan de estudios lo integra un conjunto sistemático de ejercicios metódicos encaminados al aprendizaje de las ciencias superiores, a saber, la filosofía y la teología, y cuyo conocimiento conviene a los religiosos para que atiendan con experticia todos los menesteres eclesiásticos (Salazar, 1946, p. 4). La diferencia entre los estudios conventuales de los universitarios estriba en que los últimos tienen el derecho conferido por la autoridad de la Iglesia a emitir grados académicos.

Los conventuales fueron impartidos por los hijos de Domingo de Guzmán en el Convento del Rosario de Santa Fe de Bogotá, y su existencia se remonta al año de 1550. Este fue un lugar de formación para muchachos, hijos de conquistadores encomenderos, siendo algunos religiosos, quienes, al recibir los hábitos, oficiaban como curas tanto en las ciudades como en los Pueblos Indios (citado por Abel Salazar de Zamora, 1946, pp. 103-104). Fray Alonso de Zamora, el historiador dominico, se refiere a este centro de estudios como un lugar en el que los hijos de los conquistadores se preparaban en los conocimientos de la gramática y de la doctrina sagrada o religión. Tiempo después se instituyeron las facultades de Artes y Teología. En el año de 1563, las lecciones de gramática comenzaron a ser oídas por seculares y religiosos.

Las universidades fueron concebidas por la orden de predicadores en grado sumo, queriendo decirse con esto que "a ellas se dirigía a perfeccionarse la flor y nata de la juventud estudiosa; la que habría de desempeñar después las cátedras y otros cargos de relieve" (Salazar, 1946, p. 101). Es decir, que la élite neogradina debía pasar necesariamente por la Universidad Tomística de Santafé para acreditar su abolengo y sobre todo para ganar un cargo público tanto en la burocracia eclesiástica como en la civil. 
Crear un centro de enseñanza en grado sumo en el siglo XVI implicaba necesariamente tomar por referente la Universidad de Salamanca, sobre todo en una época de florecimiento intelectual, atravesada por las principales corrientes filosofías del humanismo renacentista, a saber: el racionalismo, el iluminismo erasmista y el originado en la mística y las tendencias educativas renovadoras (Juan Luis Vives), como también de un tomismo que se oxigenaba del ambiente intelectual moderno, que si bien es heredero del teocentrismo medieval, no actuaba a espaldas del antropocentrismo de la época, particularmente de la inflexión histórica que se produce con el descubrimiento de América, tal y como se dejar apreciar en los trabajos jurídicos y teológicos de Bartolomé de las Casas, Melchor Cano, Domingo de Soto, Francisco de Vitoria, entre otros. Fue esta ilustre generación de dominicos la que hizo hincapié en el papel moral y jurídico que debía desempeñar la evangelización de las poblaciones recién descubiertas en las colonias de ultramar, a contrapelo del derecho real y pontifico que tenía la metrópoli a través de las órdenes religiosas y los encomenderos, para adoctrinar y convertir la humanidad del indígena descubierto.

\section{La Universidad de Salamanca y los comienzos de la Universidad Tomística de Santafé en el Nuevo Reino de Granada}

Fundada en el año 1218 por el rey Alfonso IX, la Universidad de Salamanca es la más antigua de España. En el año 1254 fue reconocida por el papa Alejandro IV como una de las cuatro mayores universidades del mundo, junto con las universidades de Oxford, París y Bolonia. A lo largo de su historia, ha contado con numerosos profesores distinguidos, tales como el fraile agustino Luis de León, Beatriz Galindo, los teólogos dominicos Melchor Cano y Francisco de Vitoria hasta el filósofo Miguel de Unamuno, y 
muchos habitantes famosos se han paseado por los pasillos de la Universidad, como Miguel de Cervantes, Hernando Cortés y Cristóbal Colón.

¿Por qué relacionar la Universidad de Salamanca con las instituciones universitarias que se crearon en América en el siglo XVI? Como lo ha puesto de presente la investigación de sor Águeda Rodríguez Cruz, particularmente en sus dos volúmenes de la Historia de las universidades hispanoamericanas (Bogotá, 1973), la influencia de Salamanca fue decisiva en la creación de las universidades en las colonias de ultramar, y de una filosofía educativa fundamentada en el tomismo renacentista o, como lo ha narrado el historiador Belda Plans, en la difusión de una escolástica renovada y atemperada por los nuevos tiempos y que se venía gestando el siglo XVI en la Universidad de Salamanca. Como institución universitaria de estudios superiores, Salamanca se ofrecía como el modelo a seguir, sobre todo en el cambio de régimen que procuraron los frailes dominicos desde 1571, al querer pasar de un centro de estudios eclesiásticos, que fue el Convento del Rosario en Santafé, a una Universidad Pública, y que se concretó con la existencia pontifica en 1580 de la Universidad Tomística de Santafé.

Los padres dominicos comenzaron los trámites para la creación de la universidad en el año de 1573 (Rodríguez, 1980, p. 267). Empezando como un centro de estudios para religiosos en el Convento del Rosario de Santafé, será fray Juan Méndez quien representará los deseos de la Orden de Predicadores ante el rey Felipe II, particularmente en la petición de elevar a categoría de Universidad los estudios en artes y teología que se venían impartiendo en el convento desde el año de 1571 (Rodríguez, 1980, p. 267). Esto se expresa en la cédula del 10 de noviembre de 1573 dirigida a la Audiencia de Santafé. Una larga espera de siete años tendrá como resultado que en 1580 los frailes dominicos reciban feliz noticia de su petición, sellándose una aceptación pontifica con la bula Romanus pontifex emitida por el papa Gregorio XIII, y 
en la que se fecha canónicamente el comienzo de la Universidad Tomística de Santafé en el Nuevo Reino de Granada. A juicio de la historiadora Águeda Rodríguez:

La bula facultaba la erección de una universidad de estudios generales en el convento de Santafé, con rector, lectores y facultades según las costumbres de la orden, con autorización para poder explicar todas las disciplinas de cualquier facultad. Los alumnos podían ganar curso y recibir los grados académicos acostumbrados en las demás universidades, de manos de sus rectores, doctores y maestros diputados para ello. Por último, concede a la Universidad todos los privilegios de que gozaban los que se graduaban en las universidades españolas (Rodríguez, 1980, pp. 267-268).

Para la historiadora, esta bula, al autorizar la creación de una Universidad en el convento del Rosario, es de un modo implícito un traspaso de la institución universitaria que representaba Salamanca en España, dentro de las dinámicas locales que consideraron los frailes dominicos deberían replicarse al Nuevo Reino de Granada. Este traspaso se hace con el mismo talante que motivó la creación de dos de los centros de enseñanza universitarios más prestigiosos en América y que emulaban directamente a Salamanca tanto en la Nueva España como en Lima. Ello quiere decir que el modelo pedagógico de la época fue apropiado miméticamente, importando al continente prácticas, currículos y enfoques filosófico-teológicos. La institución académica en América Latina fue por costumbre una réplica del régimen universitario español, cuyo emblema y fortín era la Universidad de Salamanca. La emisión de grados se convierte en el privilegio que abroga la bula a la naciente Universidad Tomística y que la hace próxima a la salmantina y a sus hijas mayores en México y Perú.

Pero si bien la existencia pontifica de la Universidad se comprueba con la bula Romanus de 1580, solo hasta principios del siglo XVII logra resolverse en la práctica la financiación para su 
fundación. Y ello gracias a los treinta mil pesos que dejó Gaspar Núñez, quien en 1608 ordena a sus albaceas que la administración de los dineros fuese asumida por la orden de predicadores, quienes debían destinar los recursos en el sostenimiento tanto del Colegio de Santo Tomás del Rosario, que deja de ser convento, como de las cátedras de artes y teología. La conversión del Colegio de Santo Tomás del Rosario a Universidad se materializará entre 1604 y 1644, periodo en el cual se logran resolver las autorizaciones por parte tanto del maestro general de la Orden como de los permisos que se otorgarán en Roma (Rodríguez, 1980, pp. 270-271).

\section{La segunda escolástica española y el humanismo individualista}

Con el nombre de la Segunda Escolástica Española se conoce el movimiento intelectual que tiene como fortines académicos la Universidad de Salamanca y la Universidad de Coimbra desde el siglo XVI hasta el siglo XVII.

A lo largo del siglo XVII la situación vivida en las colonias americanas se presentaba en la práctica como un escenario dominado por las disputas jurídicas y políticas que se venían ambientando en la Segunda Escolástica Española, y que para la historia de la orden dominicana tuvo su origen en buena parte de la generación de académicos e intelectuales pertenecientes a la escuela de Salamanca. Para Joaquín Zabalza Iriarte, O. P. (1992), la filosofía práctica en la colonia estuvo ambientada por una escolástica que se caracterizó en el esfuerzo sistemático de aplicar las doctrinas de la Suma de Santo Tomás, a los problemas desatados con la legitimidad de la conquista, entre los que cabe resaltar el derecho a la propiedad en el territorio descubierto, el derecho de gentes y de guerra, el gobierno de los indios, la evangelización y todo el 
proceso de adoctrinamiento que acompañó el proceso educativo instaurado y administrado por las comunidades religiosas (franciscanos, dominicos, agustinos recoletos y jesuitas).

La idea de la libertad en la tradición

humanista de la escuela de Salamanca

En el caso de la orden dominicana, la tematización del concepto de libertad adquiere una especial relevancia en la tradición Salmantina. La renovación de la escolástica española combinó elementos provenientes del humanismo europeo, con un giro exegético al interior del modelo educativo conventual, al acoger la Suma de Santo Tomás como libro de texto universitario (Belda Plans, 2000, p. 207).

Fueron elementos característicos de esta renovada teología escolástica el cultivo de una escritura menos científica y especulativa, por una más a fin al estilo literario y convincente del humanismo erasmista y del siglo de oro español; una vocación pastoral más práctica y atenta a los acontecimientos desatados con el descubrimiento de América; la paulatina separación del espíritu cerrado y dogmático de la vieja escuela medieval, por una más abierta a la discusión y a la diversidad de los enfoques metafísicos (tomismo, escotismo y nominalismo) (Belda Plans, 2000, pp. 208-209).

\section{La noción de libertad en el pensamiento jurídico de los siglos XVI y XVII}

La indagación jurídica que propone la segunda escolástica parte del a priori moral de la libertad. Esta idea, con sus matices particulares es latente en la filosofía práctica de Guillermo de Occam (12851347), Duns Scoto (1266-1308) y Santo Tomás (1225-1274). En síntesis, la segunda escolástica propondrá tres grandes ejes sobre 
los cuales se fundará el pensamiento jurídico del siglo XVI y XVII: a) la libertad, entendida a la manera de una 'exclusiva ontológica del ser moral' aplicable a la totalidad de los hombres, e interpretada como la condición inicial para toda invención artificial de carácter contractual (derecho positivo); b) una concepción voluntarista de la fe, y c) una antropología individualista que comprende al hombre como una realidad acabada.

La indagación jurídica planteada por esta escolástica leerá el concepto de libertad bajo el influjo de la cultura humanista. Un humanismo cultivado por Erasmo de Rotterdam (1466-1536) y Juan Luis Vives (1493-1550), intelectuales que propondrán una antropología filantrópica, que apreciará la naturaleza humana como una potencia en constante autorrealización; el regreso a la antigüedad clásica grecorromana y a una filología consagrada al descubrimiento de las fuentes y el cuidado de la forma literaria; al acercamiento entre la lógica y la retórica, método usado en las argumentaciones de los dialécticos (Belda Plans, 2000, p. 247). La cultura humanista determinará el contractualismo iusnaturalista, formulado por Francisco de Vitoria (1483-1546), quien planteará la soberanía del pueblo (democracia), como única forma de gobierno que se ajusta a la ley natural.

Una de las notas predominantes del humanismo del siglo XVII es un particular acento individualista. La filosofía de la conquista no fue precisamente una escolástica jerarquizada y racionalista, sino una de corte humanista que se acercaba a la particularidad histórica de las víctimas, relatando sus dramas en los procesos de colonización y explotación de territorios y comunidades indígenas, poniendo al descubierto la barbarie de los perpetuadores de un proceso de conquista sanguinario y cruel. La forma se impuso como una manera de retratar la injusticia perpetuada por la empresa de la conquista. El estilo literario y el embellecimiento del lenguaje fue también una herencia de época dominada por el humanismo renacentista y el siglo de oro español. Como se describe 
en la publicación La Universidad Santo Tomás de Colombia ante su historia siglos XVI $y$ XIX.

De los escolásticos, los humanistas conservan las ideas de "dignidad del hombre" y de "microcosmos", pero consideran que su comprensión exige recuperar el antropocentrismo grecolatino puro, cuyos modelos estéticos hay que imitar. La valoración positiva de lo humano (frente a lo inhumano o lo bárbaro) se constituye como telón de fondo y como sensibilidad compartida de las consideraciones morales, religiosas, artísticas y políticas. La "dignidad del hombre" se convierte en categoría articuladora de las realizaciones del espíritu humano. (Plata, Reyes, Moreno, Rodríguez, Vol. 1, 2005, p. 52)

El cristianismo colonial: la universidad como el espacio de la reconquista espiritual en las colonias americanas

Con el término de cristianismo colonial pretendemos significar que dicha doctrina religiosa fue un instrumento del poder imperial usado por la metrópoli para la administración de las tierras en las colonias de ultramar, a través de la tutela espiritual y el dominio ideológico y moral de las poblaciones étnicas descubiertas. La iglesia asumió el poder colonial sobre los territorios americanos, buscando fundamentalmente dos cosas: la explotación de la riqueza y la cristianización de los hombres. Los reyes católicos y sobre todo Carlos V buscaron la unificación de toda Europa "bajo el signo de la cruz y de la iglesia católica" (Bastian, 1992, p. 33). Seguimos a pie juntillas la descripción del concepto propuesta por el investigador Jean-Pierre Bastian:

La Iglesia, pilar del orden colonial, se convirtió en un canal de ascenso social para las capas de la población blanca y mestiza, en tanto que los indios y los negros no tenían acceso al sacerdocio. Su hegemonía sobre la sociedad civil fue total, puesto que 
una parte de la riqueza eclesiástica fue redistribuida en forma de servicios: hospitales, orfelinatos, escuelas, residencias para pobres y ancianos. Una de las tareas fundamentales de la Iglesia fue la educación, área en la que se aseguró un monopolio para formar las élites. Esta Iglesia colonial reprodujo sin duda los modelos metropolitanos de Iglesias ibéricas. A nombre del derecho de Patronato, ejercido por la monarquía española y portuguesa, ella dependía directamente de los centros metropolitanos y no de Roma. La Iglesia, instrumento del poder real, contribuyó a estructurar un modelo de sociedad, conforme a los ideales de la contrarreforma, cuyas directrices fueron rápidamente aplicadas a todos los espacios coloniales (Bastian, 1992, p. 35).

La existencia de la Universidad en las colonias de ultramar no se apartaba de este proyecto histórico en el que se encuentra la Iglesia entre los siglos XVI y XVII. La educación confesional, además de asegurar los puestos civiles de las nacientes élites gobernantes, propendía por una rigurosa atención a los estudios, en aras disciplinar la moral en función de la castidad y el desapasionamiento de los eclesiásticos a los intereses del mundo secular.

En este orden de ideas, una evidencia documental que comprueba lo dicho anteriormente son las Declaraciones y Ordenanzas del Capitulo General, emitidas por las constituciones celebradas por la Orden de Predicadores dadas desde el año 1220 hasta el año 1659, y en donde se señala que el núcleo de la formación confesional era el estudio de las Santas Escrituras, en aras de contemplar y comunicar lo contemplado. La raíz de este proyecto educativo se propone extirpar los deseos de la carne y alejar al estudiante de todo lo relacionado con los apetitos mundanos, la codicia y la riqueza:

Es muy conveniente para la Orden de los Predicadores el estudio de las ciencias sagradas a las cuales sirven como siervas las artes inferiores y las ciencias, porque es propio de la vida contemplativa, pues la contemplación que se dirige correctamente 
por el estudio se inclina a las cosas divinas, tanto porque nuestra orden religiosa ha sido establecida para transmitir a los demás lo contemplado, lo cual no puede hacerse sin el estudio, y finalmente porque el estudio sirve para vencer la lascivia de la carne, para reprimir y restringir la codicia de riquezas, también sirve para proseguir aquello en lo cual somos instruidos. (Ex cosnt. Nostr. dist. 2. Cap. 14. Tex. 1. Lit. A.)

Otra serie de variables históricas dan cuenta de la naturaleza social y política que se generaba a partir del modelo universitario conventual. Entre sus características se pueden distinguir las siguientes: a) la relación centro periferia, b) misión evangelizadora de las órdenes religiosas, y c) la función social de la universidad colonial.

\section{a) La relación centro periferia}

La organización de universidades y colegios mayores en el Nuevo Reino fue una prioridad fundamental para España, la más grande potencia imperial de la época, ya que la academia ejercía como instrumento colonizador. Como señalan los estudios de la Universidad Tomística, se podría entender la conquista como una prolongación de la cruzada de reconquista, practicada por el poder imperial de los Haubsurgo con sus reinos cerrados unidos a la corona. España se concebía como una federación de reinos con su propia autonomía, por lo que los estudios eclesiásticos estuvieron ligados al poder real para fortalecer el concepto de Estado-Nación.

Pero eso acontece básicamente porque la universidad es una institución que posee una realidad social. Su existencia histórica data de la Edad Media, y al proponerse como organización articular la diversidad en la unidad, sus primeras conformaciones sociales son gremiales, nominándose: corpus, collegium, communio, societas o consortium. 
La razón de ser de estas sociedades gremiales medievales, que convergen como una entidad donde la multiplicidad es agrupada en la unidad, consiste en velar por una vida dedicada a la academia. Políticamente las universidades son en su origen instituciones autónomas de carácter académico, por tres razones básicas: 1) establece estatutos corporativos que le permiten ejercer actos autónomos internos; 2) al ser sociedades dedicadas al studium (estudio, dedicación), configuran un nuevo orden jurídico (derechos y deberes) que lo desmarcan del imperium (poder político) y del sacerdotium (poder eclesiástico), y 3) como una asociación corporativa o collegium, las agrupaciones de intelectuales que aparecen en los siglos XII y XIII se dnominan bajo el nombre de 'studium generale'.

\section{b) Misión evangelizadora de las órdenes religiosas}

La labor misionera comandada por las órdenes religiosas creó un nuevo orden temporal en el imperio, siendo el propósito principal la conquista espiritual como instrumento evangelizador. La idea era realizar un trasplante total de la vida española a América, para así lograr la conversión espiritual del indígena y su transformación a la vida civilizada. Mantener un esquema ideológico cerrado e imperante fue el propósito evangelizador de la academia en el siglo XVII. En el documento se opuso al cuestionamiento de la santa doctrina era una herejía y se castigaba duramente. El documento sobre las Declaraciones y Ordenanzas del Capitulo General es taxativo al señalar que cualquier intento de duda o pronunciamiento contrario a los principios cristianos inculcados por la orden son mal vistos y hay que evitarlos.

Que de ninguna manera se expongan en las tesis una propuesta que pueda ser motivo de ofensa para el poder eclesiástico o laico - Roma 1777 acerca de los estudios. Ordenación 9-: "En las Tesis que suelen proponerse, no solamente en público sino también en privado, para ejercitar el ingenio, de ningún 
modo se exponga una propuesta que pueda ser ofensiva para el poder eclesiástico o laico; y que no se aceptan controversias de las que puedan surgir mal entendidos para la Orden". (Ex cosnt. Nostr. dist. 2. Cap. 14. Tex. 1. Lit. A.)

En otro apartado del mismo documento se hace un mayor énfasis en la combinación entre fe cristiana y estudio inquebrantable, de tal modo que el proyecto evangelizador en la perspectiva de un cristianismo colonial que se imparte en la universidad combina el espíritu académico con el carisma evangélico, sendero sobre el cual deben transitar los miembros de la orden de predicadores como caminos idóneos:

Entre las partes más importantes del deber encomendados a nosotros consideramos con debida razón el incremento de los estudios ya que la Sagrada Orden nuestra se estableció para la predicación y el ministerio de la palabra divina y su principal fin es: Iluminar a los que residen en las tinieblas y las sombras de la muerte. Para encaminar sus pies hacia el camino de la verdad y a los senderos de la justicia, por eso cada uno de nosotros por la fuerza misma de su vocación está obligado a tener en cuenta la lectura y la doctrina, en insistir en ellas para ser capaz de exhortar en la doctrina sana y para convencer a los que la contradicen. Por eso, desde los comienzos de nuestra Orden, siempre fue tan grande la preocupación y la solicitud entre nuestros Padres por los progresos de los estudios y el aprovechamiento de los estudiantes; esto no solo es vigente por los innumerables varones de excelente doctrina que desde el principio a promovido nuestra Orden hasta el día de hoy, sino también por la constante vigilancia de los Capítulos Generales que no han dejado sin intentar nada para cuidar y promover cada vez más los estudios de las ciencias divinas en nuestra Orden. (Ex cosnt. Nostr. dist. 2. Cap. 14. Tex. 1. Lit. A.) 


\section{c) La función social de la universidad colonial}

La función de la universidad colonial buscó adscribir súbditos americanos al imperio y, en general, al sistema de jerarquías de la sociedad española, con la posterior aculturación y conversión, bajo la justificación de la superioridad racial y la imposición del derecho de guerra. Se trataba de utilizar la educación y la cultura con el fin de humanizar al indio, servir a los intereses de la corona reforzando los lazos con la metrópoli.

En medio de todo este ambiente político y académico se conformaron los estudios eclesiásticos en el Nuevo Reino y el régimen legal de la universidad colonial, que funcionaba de acuerdo con la Bula pontificia de erección, siendo a la vez institución pontificia y real. En la Recopilación de Leyes de Indias de 1680 se incluyen leyes sobre aspectos universitarios, clasificando los estudios en generales y particulares, los primeros mayores y considerados como reales, con intervención de la Corona en su organización.

Los estudios superiores fueron una exigencia para acceder a determinados cargos públicos, que estaban previamente controlados por rígidas formas de selección para su asignación, fueran civiles o eclesiásticos, con unos requisitos bien estipulados. La escolástica y el tomismo eran los pilares más importantes del sistema educativo hasta finales del siglo XVIII al margen del desarrollo filosófico-científico, prevaleció una formación en teología moral que daba un fundamento ético para la acción que le permitía al educando acoplarse al sistema legal y político con todo un sistema ético que sirviera para la elección y deliberación, para la toma de decisiones que reproducían el poder del gobierno colonial.

La corona vio en las instituciones religiosas o clericales la posibilidad para capacitar a bajo costo tanto a criollos como a españoles en las tareas administrativas y burocráticas en las que se ataba la relación entre la metrópoli y las colonias de ultramar. Esta es una de las tesis que se desprenden de las investigaciones adelantadas por la historiadora Sor Águeda Rodríguez a propósito de la 
influencia de las corporaciones universitarias fundadas desde el siglo XVI en Hispanoamérica y la corona española, que al apoyar la multiplicación de estos centros educativos facilitaba la inserción de los hijos de 'sus reinos de las Indias' en las necesidades "sociales, educativas, evangelizadoras, administrativas, judiciales de gobierno" (Rodríguez, 2005, p. 13).

\section{Libertad, autoridad y laicidad: la formación integral en perspectiva al proyecto educativo dominicano}

Una de las cuestiones que se desprenden de la relación de aprendizaje entre el educador y el educando se identifica en la dinámica de dos conceptos que marcarán el sendero de cualquier relación pedagógica: nos referimos a la relación entre la libertad y la autoridad. Tal y como los describe José de Jesús Sedano González, O. P., en la Pedagogía de la respuesta (Bucaramanga 2002), la libertad la reclaman quienes aprecian el valor del aprendizaje en la espontaneidad y la autonomía sin ataduras; la autoridad la exigen quienes ponen en primer lugar la administración del poder para organizar la comunidad humana a partir de una jerarquización donde predominan el verticalismo y la obediencia. La enemistad entre estos dos extremos del devenir educativo producirá comportamientos anómalos y enfermizos tanto en el educador como en el educando, que estarán en detrimento de la construcción de un proyecto educativo que le apuesta a la integralidad, es decir, que piensa un ideal formativo en el que se iluminará un camino para hacer posible la promoción de una persona en el conjunto de las dimensiones humanas, a saber, las espirituales, las socio-comunicativas, las ético-políticas, y las práxico-poiéticas. Esto no es otra cosa más que la descripción de un proceso educativo cuya finalidad busca las maneras de vincular el saber, el ser y el hacer. 
Entre las patologías que se desprenden de una relación contradictoria entre los términos mencionados, se origina desde la apatía, la indiferencia o la sumisión y la acritud, hasta el autoritarismo, el dogmatismo o el despotismo ilustrado. Como lo describe el padre Sedano, esta lucha recrea un deporte tan trágico como destructor:

De un lado, el dominio autocrático y su reverso, la sumisión servil, van fomentando, a la larga o a la corta, la reacción rebelde; y, de otro lado, conquistada la independencia, nadie se arriesga a una libertad comprometida por un nuevo orden: los unos, por miedo a perder, cundo no las riendas del poder, el prestigio de su función formadora; y los otros, por miedo a perder, cuando no el goce de una iniciativa individualista, el gusto y el regusto de la espontaneidad. (Sedano, 2002, p. 49)

En el devenir del proceso educativo surge de manera inevitable la confrontación entre las cuestiones sugeridas por el padre Sedano: "¿Autoridad magisterial impositora y, de contrapartida, sumisión pasiva en el educando? ¿Espontaneidad del educando y, como el reverso de tal actitud, un "dejar hacer" a la deriva por parte del educando?” (Sedano, 2002, p. 45). Abría pues un concepto negativo de la libertad cuando el sujeto se declara libre de los vínculos y las ataduras con el otro y hace lo que quiere; o, por el contrario, el educando sabe que el enderezamiento de una libertad negativa pasa necesariamente por el cuestionamiento de una autonomía caprichosa y deseante, con miras a la materialización de una acción comprometida con los otros y con el otro. La libertad negativa es pues la libertad comprometida por excelencia.

Sin embargo, las consecuencias más inmediatas de un proceso educativo cuya mediación es el dejar hacer, el dejar pasar, son la anarquía y la 'espontaneidad libre y desatada' (Pedano, 2002, p. 49); la forma más inmediata del modelo autoritario es "la represión 
bajo el signo del orden y de la seguridad colectiva" (Sedano, 2002, p. 49). En la esquizofrenia de estos extremos 'seudopedagógicos' se siembra el miedo a la libertad:

Miedo a la libertad por parte de los detentores del poder, que no se resignan a perder la conducta autocrática de la colectividad; miedo a la libertad comprometida en un proyecto solidario y exigente, por parte de quienes han conquistado a costa de heroicos esfuerzos, la libertad de espontaneidad. (Sedano, 2002, p. 51)

La pregunta acerca de si la fuerza de la educación proviene del educando o del educador es una cuestión que históricamente tendría relación con el surgimiento de la Orden de Predicadores en el siglo XIII. Siguiendo los planteamientos del historiador G. De Lagarde, el padre Sedano considera que el siglo XIII fue una época decisiva en la aparición de un fenómeno social determinante para Occidente: el 'espíritu laico'. Dicho espíritu es la toma de conciencia del pueblo europeo de sus 'derechos y libertades': en la crisis de la estructura feudal tendría lugar de aparición esta conciencia de los derechos, que cambiaría sustancialmente el concepto de la 'solidaridad vertical', puesto en práctica en la relación de vasallaje entre un señor y los súbditos o siervos, para pasar a una 'solidaridad horizontal', en donde el juramento de fidelidad ya no se hacía entre los vasallos y el señor feudal, sino que involucraba un proyecto en común. El origen de las comunas en la Europa moderna se encuentra en la conformación de las primeras 'corporaciones socioeconómicas' que vendrán a estructurase en 'corporaciones de estudios o "universidades de estudiantes y maestros"” (Sedado, 2002, p. 54).

Las corporaciones universitarias iniciaron como comunidades religiosas que al poner en práctica la 'vida apostólica' explicitaron un proyecto de renovación en la Iglesia; proyecto que se proponía 
abanderar los procesos comunales agenciados por una laicidad que reclamaba derechos, en medio de las contradicciones de una estructura feudal que excluía la gleba empobrecida tanto de campesinos como de artesanos, quienes contaban con la solidaridad de algunos de los hijos de los señores feudales (Sedano, 2002, p. 55). El origen de las universidades medievales está asociado con la existencia de las primeras corporaciones laicas, que al reclamar la emancipación frente al poder feudal dominante fueron las que agenciaron las iniciativas por la creación de un modelo educativo y cultural diferente. Las cuestiones abordadas por Santo Tomás entre los años de 1257 y 1258, sobre todo en su obra pedagógica por excelencia De Magistro, explicitarán la confrontación entre el régimen feudal y las iniciativas culturales y educativas que adelantaban los de la Orden de Predicadores, quienes promovieron el espíritu misional de Domingo de Guzmán, a saber: estudiar, predicar y fundar conventos.

\section{Conclusiones}

¿Cómo situar la dialéctica pedagógica y filosófica de los conceptos de libertad y tradición en los escenarios humanísticos de la educación universitaria actual? Definitivamente, el ideario libertario como el legado de los saberes tradicionales cultivados al inicio de las corporaciones universitarias conventuales desde el siglo XVII en la América hispánica ha tenido transformaciones significativas para las apuestas sociales y educativas demandadas para el siglo XXI.

Particularmente en el contexto de las sociedades democráticas que, a juicio de los especialistas, su idea de cualificación, progreso y desarrollo está determinada por el índice que arroja el producto interno bruto, dato que aseguraría los rendimientos del despliegue económico de una nación. Este balance económico presenta la dificultad de medir la riqueza de las naciones sin atender a las 
condiciones en la calidad de vida de las poblaciones. En otras palabras, para el Fondo Monetario Internacional (FMI) la prosperidad económica de una noción puede ser valorada como positiva, prescindiendo de las condiciones adversas y hasta contradictorias en las que vive una sociedad. Los cambios sustantivos de una sociedad pasan por la decidida transformación de las prácticas educativas y las apuestas pedagógicas que propenden por una reivindicación de los saberes heredados y su implementación en los planes curriculares que reciben los profesionales que harán parte de las dinámicas del mercado. Sin embargo, un proyecto educativo de tales dimensiones debe sortear por una serie de obstáculos.

Por ejemplo, en los Estados Unidos el modelo de educación en humanidades ofrece para los dos primeros años universitarios una amplia variedad de estas materias. Históricamente no se ha visto como un privilegio restringido a una élite letrada, sino que los primeros especialistas en educación indicaron que la implementación de las humanidades en los planes de estudio forma a ciudadanos que defenderán los derechos civiles que promulga la carta constitucional. De otra parte, la filosofía educativa que ha pensado la orientación pedagógica en la educación primaria y secundaria estadounidense plantea que la investigación y la actitud inquisitiva son necesarias para un tipo de aprendizaje que garantice el compromiso moral y el pensamiento crítico.

Los filósofos y pensadores que apertrechan de enfoques y concepciones éticas y educativas de un modelo crítico de enseñanza son Rousseau (1712-1778), Dewey (1859-1952), Fröbel (17821852), Pestalozzi (1746-1827), Bronson (1799-1888) y Montessori (1870-1952). Estos autores como sus principios de orientación aún se resisten a ser desechados en la tradición educativa norteamericana, a pesar de las presiones por formar un alumno a la medida de las exigencias de un mercado que no le interesa tener en sus huestes un espíritu crítico. Otro ejemplo significativo es el modelo pedagógico que propone Rabindranan Tagore (1861-1941) para 
la universidad Visva-Bharati, que antiguamente se soportaba en una formación interdisciplinaria en artes y humanidades, y hoy ha sido remplazada por el modelo de las disciplinas profesionales.

Frente a la pregunta del tipo de educación que estaría apoyando el modelo del crecimiento económico, Martha Nussbaum (2010) sostiene que una formación en matemáticas, en tecnología e informática colmaría las expectativas para los grandes empresarios, quienes tendrían a su disposición una amplia gama de trabajadores o élite formada en los saberes técnicos, dispuestos a asegurar los índices de crecimiento económico de los pueblos. En ciudades indias como Gujarat y Pradesh, se encuentra una amplia gama de poblaciones con conocimientos técnicos que atraen a la inversión extranjera. Así mismo, los programas de formación universitaria en estos lugares prescinden de una formación en las artes liberales, justamente porque a los grandes empresarios no les interesa que sus trabajadores tengan un espíritu crítico, sino más bien de obediencia y sumisión. Este tipo de formación, que en apariencia aseguraría el crecimiento económico, garantizaría un fuerte sentido de pertenencia nacional (nacionalismo), pues las huestes de trabajadores de las regiones aumentarían sus ingresos, ampliarían las expectativas de una mayor inversión extranjera si los índices del PIB los favorecen respecto de otras regiones. Se trata de un nacionalismo que ama el mercado, pero no los valores genuinos de la virtud política que la representa: el patriotismo.

Sin embargo, esta tendencia pronunciada por un nacionalismo de los mercados olvida las críticas que haría Tagore en una serie de conferencias donde el pensador indio sugiere la relación que existió entre el nacionalismo y el fratricidio desatado entre las naciones europeas para la Primera Guerra Mundial en Europa.

El panorama que describe Nussbaum a propósito del modelo del crecimiento económico promovido por la formación en ciencias básicas de la informática y las tecnologías busca crear una élite de técnicos prestos a ingresar a las grandes factorías, ubicadas 
por empresarios que mueven las transnacionales por las regiones donde los índices de alfabetización en los saberes técnicos son altos. De otra parte, esta población de trabajadores estandarizados goza de un reconocimiento social por parte de las familias, mientras quienes optan por las profesiones humanistas suelen caer en el descrédito y la vergüenza familiar. Así mismo, la falta de pensamiento crítico se ha ido consolidando en estas generaciones de trabajadores, quienes se convierten paulatinamente en una masa uniforme donde predomina un sentimiento chauvinista, que peligrosamente generará la xenofobia, el racismo, y en general los síntomas de una sociedad donde sobresalen los deseos de frustración, venganza y resentimiento, un caldo de cultivo ideal para las guerras futuras y el fascismo.

Contrario al diagnóstico de barbarie que describe Nussbaum, es un hecho indiscutible que uno de los aportes decisivos de la Universitas medieval consistió en la relación que se plantea entre el conocimiento erudito y su relación con la sociedad. Las primeras agremiaciones colegiadas de hombres de letras o asociaciones espontáneas de intelectuales alrededor del studium generale son un ejemplo patente de que la universidad ha colaborado con el bien común de la sociedad.

Los maestros medievales cohesionados en el gremio universitario aprendieron de Cicerón que la sensatez de las acciones es una combinación de memoria, inteligencia y prudencia. La memoria es el ejercicio de mirar hacia atrás, la historia que permite leer el presente. La inteligencia, una capacidad al servicio del razonamiento del pasado que busca mostrar su relación con la actualidad de los hechos y de las cosas. Y la prudencia, el juicio práctico por excelencia, es la habilidad para pre-ver, anticiparse y confiar.

Estas virtudes humanas, que fueron enaltecidas con la teología de la virtud cristiana, perfilaron un tipo de maestro y educador medieval, que anticipaba la venida del hombre en lo superior y 
para lo superior, cuyas notas predominantes serán la prudencia y la honestidad. Uno de los objetivos de la educación que promueve la Universidad Santo Tomás consiste en la formación de personas que despliegan su humanidad en la totalidad de sus potencias volitivas, emocionales. Intelectuales, sociales y técnico-profesionales. La persona es una conquista espiritual y emocional que se construye en un proceso formativo humanista incluyente, crítico, dialógico y abierto, que, antes de reconocer el tener, se preocupa por un modelo educativo que promueva un modo de ser auténtico, solidario y comprometido con la idea de que el conocimiento profesional está al servicio del mejoramiento de la calidad de vida de las personas.

Finalmente, la filósofa plantea una serie de mínimos fundamentales que estarían detrás de una formación democrática humana y sensible:

a) Aptitudes reflexivas que permitan analizar de una manera argumentada la problemática política que aquejan a las naciones, sin tomar partido desde las nociones comunes de la tradición o la autoridad.

b) Aptitudes para reconocer en la otra persona una humanidad que posee derechos sin distinción de raza, religión, género u orientación sexual, que toma en consideración su condición de fin y no de medio.

c) La aptitud de la alteridad, esto es que se interesa por la vida de los otros, reconociendo que en cada decisión política hay una consecuencia social que repercute en las oportunidades de los otros en otras naciones.

d) La aptitud para imaginar las complejidades que afectan la vida humana en las diferentes etapas del desarrollo psico-social, relacionándolas con las experiencias axiales que constituyen también humanidad, como el amor filial, la muerte, el sufrimiento, etc. 
e) La aptitud crítica para juzgar las decisiones que determinan los poderosos, desde una mirada contextuada y situada en las posibilidades que ofrece la realidad.

f) La aptitud para pensar en el bien común, como un factor fundamental en la comprensión de los intereses de todos y no de los que gozan de manera privilegiada ciertos grupos reducidos.

g) La aptitud para pensar que los problemas locales son al mismo tiempo problemas de orden global. Se trata de reconocer que la realidad política de la propia nación se encuentra determinada por un orden mundial complejo, donde las decisiones de orden político son de naturaleza transnacional y exigen una deliberación que va más allá de los sentimientos foráneos y puramente locales.

Otra réplica que se puede hacer al modelo educativo profesionalizante tiene que ver con la capacidad de generar destrezas críticas y de investigación frente al conocimiento, en escenarios tremendamente prácticos como los generados en el aula de clase. Ken Bain (2007) formula un experimento en el que se dimensionaba el nivel de asimilación y aprendizaje que adquiere un grupo de estudiantes frente a las lecciones de física y matemáticas impartidas por profesores entrenados en esta materia y que han sido considerados como buenos en sus campos disciplinares.

Los resultados obtenidos en dichos experimentos cuestionan los alcances que puedan tener una serie de contenidos impartidos en el aula de clase, particularmente alrededor de algunos principios matemáticos y algoritmos propios de las teorías físicas modernas (sea el caso de la teoría de la gravitación universal de Newton). Dado que el estudiante si bien ingresa reconociendo algunas nociones intuitivas del movimiento, la potencia y la energía, no logra conceptualizar con precisión, ni siquiera superar las nociones del sentido común. Aun después de que la física moderna ha hecho 
progresos notables alrededor de concepciones naturalistas y esencialistas de realidades palpables en el mundo físico como lo son: el tiempo, el espacio, el movimiento, etc.

Las lecciones en clase tampoco revirtieron la situación, y ello puso en evidencia que la mayoría de los estudiantes asimilan los conocimientos impartidos por los profesores en función de las pruebas o los obstáculos que se deben resolver con los principios matemáticos. En otras palabras, el aprendizaje para la vida que pueda proporcionar la matemática y la física se resuelve a través de una actitud funcionalista y utilitarista asumida por el estudiante, que interpreta el conocimiento en relación con la solución de un problema inmediato, pero no con la conexión que pueda tener el mismo para la comprensión del mundo de la vida.

Así las cosas, la idea de enseñanza superior, ordenada bajo la figura representativa de profesores calificados como excelentes en sus disciplinas, se agota en las posibles soluciones que le permitan al estudiante resolver una serie de pruebas y ejercicios de conocimiento. $\mathrm{O}$ si por, el contrario, este aprendizaje realmente perdura en la vida, y es retenido por los estudiantes en una memoria duradera y de largo plazo, y ello para resolver no solo los obstáculos funcionales que se producen en el mundo laboral (en analogía a los simulacros de ejercicio en el mundo de la clase), sino que realmente acierta en su nivel de comprensión de la vida.

Según lo anterior y tomando por referente el modelo educativo de la Universidad Santo Tomás, particularmente en lo referente al paradigma filosófico y pedagógico del humanismo cristiano tomista, el interés de formar a la persona humana y la enseñanza a través de problemas busca de una u otra manera trascender la llana asimilación técnico-científica de los conocimientos. El modelo de la educación profesionalizante en el contexto de la globalización y de la sociedad de mercado que se encuentra a la orden del día, no contribuye en una conciencia crítica y mucho menos en el fomento del tacto y la sensibilidad moral que se necesitan para atender 
a las problemáticas sociales que se generan en el país y en el mundo, en materia de racismo, violencia de género, exclusión y condena a la diferencia de pensamiento, culto o preferencia sexual, etc.

En este sentido, preguntas como ¿qué enseñar?, ¿cómo enseñar?, pretenden describir algunas estrategias y apuestas pedagógicas que desde el escenario de la metacognición permitan reconocer por parte de cualquier ente de educación superior que el proceso de enseñanza y aprendizaje no se circunscribe a la asimilación de una serie de conocimientos técnicos dispuestos a ser aplicados en el escenario del mundo global y de mercado, sino que siempre habrá algo más, que se escapa al funcionalismo adaptativo en el que al parecer se encuentra atrapada la mente humana en el contexto actual. Y ello pensando que las formas de apreciar el conocimiento y la ciencia en general (humanas y exactas) en la Universidad tienden a desdibujar su naturaleza vital y orgánica para entronizar una finalidad mecánica y de resultados, conveniente a las dinámicas del mercado y el capitalismo actual, pero inconveniente a la hora de formar personas con un sentido crítico, personal y prospectivo y ello en la consideración de que el conocimiento no es un símbolo en un papel (diploma de grado), sino realmente el dispositivo ideal para la transformación de una realidad inhumana en donde la barbarie es la ley.

Si se parte de la premisa de que la educación humanista es una práctica social que privilegia la profundidad sobre la funcionalidad, la cooperación sobre la competencia, en fin, la humanización sobre la robotización, entonces tendríamos que apreciar la educación superior de corte confesional y humanista, como una oportunidad que tiene el profesor y estudiante no solo de entablar relaciones de enseñanza y aprendizaje en aras de aplicar soluciones a problemas de la vida práctica, sino realmente a crear interacciones de trascendencia. Hablamos de trascendencia en el sentido de que se alcanza una comprensión del mundo de una manera más integral, vital y dinámica. Dicha trascendencia interaccional 
propende por una relación pedagógica que supere una instancia técnico-operario-funcionalista, para llegar a un horizonte utópico y deseable en el que la comprensión-humanista e integral de la realidad sea la prioridad.

Pensando la pregunta ¿qué es lo que hacen los buenos profesores sobre cómo aprendemos?, podríamos situarla en la Universidad Santo Tomás a modo de alternativas y estrategias que propenden por una relación de enseñanza-aprendizaje más viva y correspondiente con la formación de la persona humana. Una formación crítica y problematizadora donde el conocimiento disciplinar dialoga con el conocimiento universal, que es fundamentalmente el que corresponde a la naturaleza instructiva de la universidad, puesto que su origen etimológico (universitas) propende por el cultivo de los saberes desde una perspectiva universal. Estas estrategias se pueden clasificar y resumir del siguiente modo:

1. Más metacognición y menos cognición: Muchas veces la formación disciplinar de los maestros suele considerarse como una prenda de garantía para la formación de los estudiantes en escenarios educativos en donde prima la calidad y la excelencia. Pero según las pruebas y experimentos con profesores destacados en sus ámbitos disciplinares, consagrados en la preparación de sus clases, que tienden a sobrevalorar la perfección alcanzada en la presentación curricular de los conocimientos programados, no generan en el estudiante cuestionamientos profundos sobre las disciplinas. Se privilegia lo contrario, mentes adiestradas y disciplinadas pero incapaces de apropiarse con creatividad del conocimiento. Para romper este círculo, Bain evoca ejemplos de prácticas docentes donde el maestro conoce la historia de la disciplina, los hitos paradigmáticos que han quebrado con el conocimiento del pasado, las discusiones epistémicas alrededor de la ciencia y su conformación en 
la historia. El ejercicio meta-cognitivo del profesor implica ir más allá de una experticia cognitiva individual. Es decir, pretende situar al estudiante en una relación de enseñanza y aprendizaje distinta, en la medida que el maestro logra discriminar en el vasto universo de los conocimientos, aquellos elementos que realmente interesan y convienen al estudiante. También hace parte de la metacognición la capacidad de distinguir las discusiones sobre el saber y las disciplinas, cuestión que favorece una apropiación más viva y real de estos conocimientos. Se trata de saber cuáles son los aspectos de su saber disciplinar que son particularmente complejos y lograr comunicarlos de un modo sencillo. En fin, es un conocedor de la motivación humana y los deseos de aprendizaje, situación que permite una apropiación más orgánica y viva del conocimiento por parte de los educandos.

2. La memoria no se recibe, se construye: Otra creencia muy común entre los profesores es la que sostiene que la finalidad cimera de una disciplina que se enseña es la de su asimilación, puesto que difícilmente podrá ser recreada o cuestionada. Esta idea la anticipa una concepción del aprendizaje en función de la capacidad de retención y recepción de conocimiento que a la manera de un archivo ordena, clasifica y guarda. Esta misma concepción es la que define la memoria como una potencia humana al servicio de la recepción pasiva y la aglutinación del conocimiento. Para Bain, los maestros que logran marcar a sus estudiantes hacen un uso distinto de la memoria, es decir, apelan a las vivencias, los prejuicios y los saberes previos que han constituido su mundo de la vida. En otras palabras, con la memoria como con el aprendizaje no se repiten fórmulas, ni se recitan lecciones de clase, sino que se construyen conocimientos. Esto ocurre sobre la base de las vivencias, el 
diálogo y la interacción en función del esclarecimiento, la explicación y la comprensión. En este sentido, el aprendizaje no es la recepción pasiva de conocimientos, fórmulas y algoritmos, protocolos, operaciones matemáticas, códigos y leyes, etc., sino recreación viva entre un mundo de experiencias diversas y materialmente ricas (que traen generalmente los conocimientos previos de los estudiantes) y modelos conceptuales, sistemas de interacción, marcos teóricos, en fin, el andamiaje disciplinar que compete enteramente a los dominios del maestro.

3. Crear las condiciones para aprender de los fracasos: Otra de las estrategias que suelen usar los maestros para poner a prueba las preconcepciones del mundo de los estudiantes consiste en deconstruirlas en escenarios de aprendizaje que cuestionan la validez de dichas opiniones. Para ello suelen desplegar un protocolo de operación en el que: 1) el modelo mental es sometido a un escenario de aplicación susceptible de caer y ser falible; 2) se insiste en el análisis de las carencias del modelo mental para profundizar en los aspectos negativos de tal modo que ello sea pretexto para la necesidad de encontrar un modelo distinto, y evitar que el estudiante recurra por comodidad este; 3) se tenga la capacidad de hacer el duelo y se motive al estudiante para que aprenda de sus errores y encamine lo mejor posible proyectos futuros, particularmente con el desafío de crear modelos mentales nuevos. Estos tres momentos crearían las condiciones para que los estudiantes aprendan de los fracasos, fundamentalmente en el cuestionamiento de sus concepciones del mundo que suelen convertirse en paradigmas inamovibles, inconvenientes para recocer que en el mundo del conocimiento los modelos cambian. Esta estrategia suele cuestionar las estrategias evaluativas del aprendizaje donde se evita el error a costa de un aprendizaje 
objetivo y certero de los conocimientos que se pondrán a prueba en exámenes con valor cuantificable. En tales diseños evaluativos el aprendizaje a través del fracaso es sustituido por la eficacia y la exactitud, cuestión que termina olvidándose una vez se ha presentado la prueba de aprendizaje. Una de las conquistas pedagógicas que se alcanzan con el aprendizaje de los errores y los fracasos consiste en sembrar en el estudiante la duda sobre sus propias maneras de aprender y aplicar el conocimiento. Lo retenido a partir de lo que se reconoce como errático perdura más que lo que se aprende en función de la solución de un examen que apela de manera exclusiva a la memoria de los datos, la información, las fórmulas, etc. En este sentido, la práctica evaluativa responderá no a la absorción de información, sino a la aprehensión de estructuras de comprensión.

\section{Referencias}

Bain, K. (2007). Lo que hacen los mejores profesores de Universidad. Barcelona: Publicaciones de la Universidad de Valencia.

Bastian, J. P. (1992). Cuadernos constitucionales México-Centroamérica. América Latina 1492-1992. Conquista, resistencia y emancipación. México: Universidad Nacional Autónoma de México (UnAM).

Belda, P. J. (2000). La escuela de Salamanca y la renovación de la teología en el siglo XVI. Madrid: Biblioteca de Autores Cristianos.

González, G. E. y Pérez Puente, L. (coord.) (2001). Colegios y universidades 1. Del antiguo régimen al liberalismo. México: Centro de Estudios sobre la Universidad. UNAM.

Nussbaum, M. (2010). Sin ánimo de lucro. Por qué la democracia necesita de las humanidades. Buenos Aires: Katz. 
Plata, Quezada, W. E., Reyes, Escobar N. C., Sánchez, Moreno, J., Rodríguez, Arévalo, A. (2005). El Colegio y Universidad Santo Tomás ante su historia, siglos XVI-XIX. Vol. I. Bogotá: Universidad Santo Tomás.

Ramírez, C. I. (2001). "Dos universidades del siglo xvi. Salamanca y México. Perspectivas de investigación". Colegios y universidades 1. Del antiguo régimen al liberalismo (pp. 17-37). Centro de Estudios sobre la Universidad. unam. México.

Rodríguez, C. M. Á., O. P. (1973). Historia de las universidades hispanoamericanas. Bogotá: Instituto Caro y Cuervo.

Rodríguez, C. M. Á., O. P. (2005). La Universidad de Salamanca en Hispanoamérica. España: Ediciones Universidad de Salamanca.

Rodríguez, C. M. Á. O. P. (1980). La Universidad Tomística de Santafé en el Nuevo Reino de Granada. En: Universidad Santo Tomás. 1580-1980. Primer Claustro Universitario de Colombia. 400 años. Universidad Santo Tomás. Colombia.

Salazar, J. A. (1946). Los estudios eclesiásticos superiores en el Nuevo Reino de Granada. 1563-1810. Madrid: Consejo Superior de Investigaciones Científicas, Instituto Santo Toribio de Mogrovejo.

Sedano, G. J. de J., O.P. (2002). La pedagogía de la respuesta. Testimonium Veritatis $\mathrm{N}^{\circ}$ 7. Convento de Cristo Rey. Bucaramanga.

Zabalza, I. J. O.P. (1992). "La filosofía colonial ¿nuestra tardía Edad Media?”. En G. Marquínez, R. Salazar, E. Rodríguez y otros (Eds.), La filosofia en Colombia. Historia de las ideas (pp. 107-133). Bogotá: El Búho. 
